\title{
Drought Potential of Paddy Fields using Temperature Vegetation Dryness Index in Kuningan Regency
}

\author{
Dian Nurhandayani Putri ${ }^{1}$, Taqyyudin ${ }^{1,}$, , Ratna Saraswati ${ }^{1,}$, and Iqbal Putut Ash-Shidiq1, ${ }^{*}$ \\ ${ }^{1}$ Department of Geography, Faculty of Mathematics and Natural Sciences, University of Indonesia, Depok - Indonesia
}

\begin{abstract}
Indonesia National Board for Disaster Management (BNPB) said that in 2002-2009 the drought was the second most frequent intensity after the flood disaster. Drought is a condition where a region experiences a lack of water. If this drought occurs in the agricultural area, it will certainly affect the plants that grow. One of the potential detection methods for drought can be using remote sensing. Temperature Vegetation Dryness Index (TVDI) is one method to detect drought potential with two parameters, vegetation index, and temperature. Through the triangle method, there is a relationship between the vegetation index and temperature represented by linear equations. These linear equations are used to calculate TVDI values. This study uses data Landsat 8 image and paddy fields. The objective of this research is how the distribution and the area of drought based on the TVDI algorithm. The TVDI with dry classes diffuse in the central and western parts, it is also the TVDI with the largest area about $155.82 \mathrm{~km}^{2}$ or $44 \%$ of the total. TVDI with wet classes can be seen in the western part of the region and the smallest area about $32.94 \mathrm{~km}^{2}$ or $9 \%$ of the total.
\end{abstract}

Keywords: Drought; Remote Sensing; Landsat 8; TVDI.

\section{Introduction}

The biggest disasters in Indonesia that occurred after the 1990 s were mostly climate-related disasters, especially floods, then droughts, forest fires and disease outbreaks [1]. Drought is basically caused by the hydrological conditions of an area under unbalanced water conditions. Drought occurs due to uneven rainfall distribution which is the only input for an area. This rainfall inequality will result in some areas with small rainfall that will experience an imbalance between water input and output [2]. When drought occurs in agricultural areas, which results in a lack of water availability needed by plants to grow so that it can disrupt the growth process called agricultural drought [3]. The Meteorology, Climatology and Geophysics Agency (BMKG) said, the results of monitoring showed that until mid-August 2018 almost all regions of Indonesia had entered the dry season at 95.03 percent.

Many studies have been carried out on drought by various methods. One technique for analyzing drought areas can use Geographic Information Systems and Remote Sensing. Landsat 8 has 11 bands consisting of visible, infrared and thermal waves. This image can be processed into several data such as vegetation and soil surface temperature as parameters. Temperature Vegetation Dryness Index (TVDI) is one of the drought indices developed by [4]. TVDI can be formulated using the value of surface temperature (LST) and vegetation index (NDVI).
NDVI is one of the image interpretation techniques. NDVI is a measure that is often used to measure the greenness of vegetation. The greenness level represented by the vegetation index is a value that has a certain interval. This index is often used to identify plant age, diseased plants, biomass, and vegetation density [5]. Land Surface Temperature (LST) is a condition that is controlled by energy balance both on land and in the air. This situation can be obtained through Landsat satellite imagery that will be extracted into a thermal band. This thermal band will be applied in a formula that will produce ToA (Top of Atmosphere) brightness temperature. This is because temperature extraction is based on the radiance value received by the sensor. TVDI is one of the parameters of the drought index based on the sensitivity of the visible and near infrared spectrum to the behaviour of vegetation and the stress conditions of vegetation associated with water shortages. On a land, generally, the vegetation index (NDVI) will increase with decreasing surface temperature (LST) [6]. The triangle method was developed by Carlson et al in 1995. TVDI describes the relationship between NDVI and LST. The dry edge indicates if the soil conditions are dry, while at the wet edge, it indicates moist or very wet soil [4]. TVDI is dryness or no humidity index where the maximum value of TVDI $=1$ shows dry pixels and wet pixels indicated by TVDI values close to 0 . [7, 8]. So, the objective of this research is :

1. How is the distribution of drought in the Kuningan district based on the value of TVDI?

\footnotetext{
* Corresponding author: ratna.saraswati@ui.ac.id
} 
2. How much the drought area in the Kuningan Regency is based on the value of TVDI?

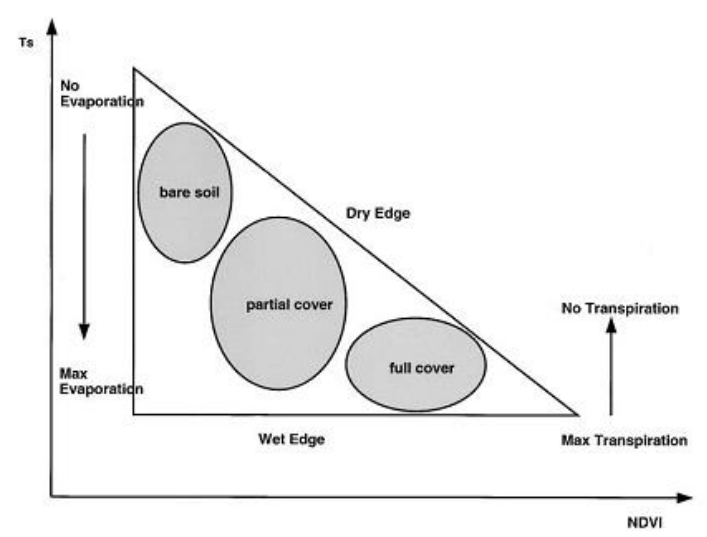

Fig. 1. Relationship between NDVI and LST $[7,8]$

\section{Methodology}

\subsection{Study Area}

Kuningan Regency is located at the coordinates of $108.23^{\circ}-108.47^{\circ}$ East and $6.47^{\circ}-7.12^{\circ}$ LS. Based on its geographical position located in the eastern part of West Java, it is located on a regional road that connects the city of Cirebon with the East Priangan region and as an alternative middle lane road that connects Bandung Majalengka with Central Java. Like other regions in Indonesia, Kuningan Regency belongs to a tropical climate.

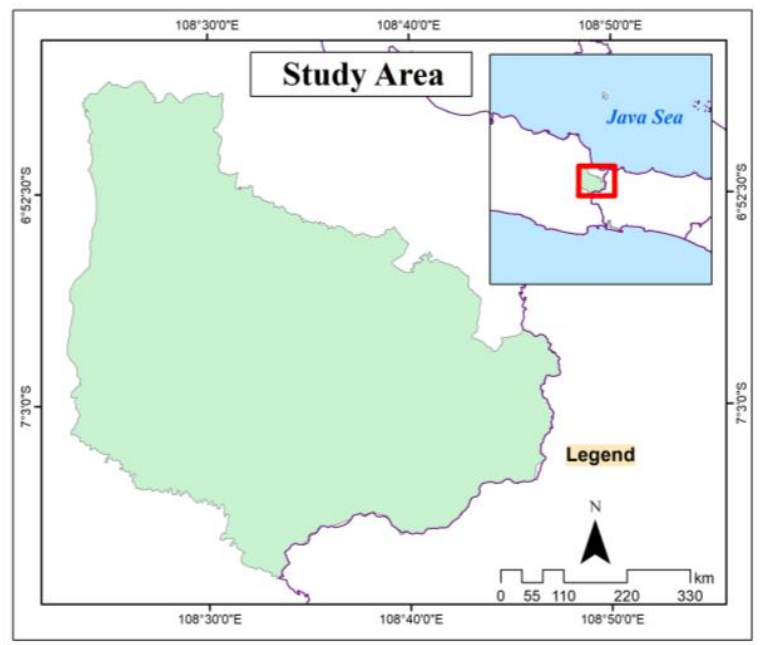

Fig. 2. Study Area

The average air temperature throughout 2018 reaches $26.08^{\circ} \mathrm{C}$, with the average minimum temperature tending to be $23^{\circ} \mathrm{C}$, while the highest maximum temperature average tends to reach $30^{\circ} \mathrm{C}$. Kuningan Regency has various heights. The eastward the lower the height, the more the westward, the higher, because in the west there is a mountain that is Mount Ciremai. Plantation becomes the largest area with an area of $318,209 \mathrm{~km} 2$ or $26.61 \%$ of the total area followed by paddy fields with an area of 193,302 or $\mathrm{r} 16.17 \%$ of the total.

\subsection{Data and Methods}

This study used Landsat 8 OLI / TRIS image that was downloaded from USGS. The image used is recording on August 14, 2018. In addition, this study also uses a map of Kuningan Regency land use obtained from the Geospatial Information Agency (BIG). The image will be processed into several values, NDVI and LST.

NDVI is an index to determine the density value of vegetation which is represented by a value of -1 to 1 . To get the NDVI value, an NIR wave and a Red wave are used.

$$
N D V I=((N I R-R e d)) /((N I R+R e d))
$$

Land Surface Temperature (LST) is processed through several stages. The Digital Number (DN) value must be converted into the spectral value of radians and the results will be converted to land surface temperature

$$
L \lambda=M_{L} * Q_{C a l}+A_{L}
$$

To get an LST, the first thing to do is to convert the Digital Number (DN) value to Spectral Radians $(L \lambda)$. Where $M_{L}$ is a scale factor, $Q_{C a l}$ is an increasing factor and $A_{L}$ is Digital Number (DN).

$$
T=K 2 / \ln \left(\left(K 1 / C V_{R 2}\right)+1\right)
$$

The second is to calculate the temperature value $(\mathrm{T})$. Where CVR is Radiance Value for thermal bands. K1 and $\mathrm{K} 2$ are constants.

$$
L S T_{\text {Celcius }}=T-272.15
$$

$\mathrm{T}$ values are represented by kelvin units. This kelvin value is converted into Celsius

NDVI is a good indicator of the condition of a plant, but cannot provide information on the condition of the soil. While LST can provide information on the amount of heat released by a surface related to the process of transpiration and evaporation. The integration of vegetation indices and soil surface temperature into TVDI is able to provide information on the description of drought on a farm (Hung and Yasuoka, 2005).

$$
T V D I=(L S T-L S T \min ) /((L S T \max -L S T \min )
$$

Where Ts is surface temperature (LST) observed in a pixel, LSTmin is minimum surface temperature, defines the wet edge, LST max is maximum surface, defines the dry edge. The TDVI value is represented by a ratio of 0 to 1 . Where the number is closer to 1 means that the area is getting drier

Table 1. TVDI classification

\begin{tabular}{|c|c|c|}
\hline No & Value & Class \\
\hline 1 & $0-0.2$ & Wet \\
\hline 2 & $0.2-0.4$ & Rather Wet \\
\hline 3 & $0.4-0.6$ & Normal \\
\hline 4 & $0.6-0.8$ & Rather Dry \\
\hline 5 & $0.8-1$ & Dry \\
\hline
\end{tabular}

Source: [4] 


\section{Result and Discussion}

\subsection{NDVI}

The band used to calculate NDVI values is Band 4 (Red) and Band 5 (NIR) for Landsat 8. The NDVI index ranges from -1 to 1 in each pixel. Pixels that have -1 are the minimum values and mean that in the region they have very low vegetation conditions. Usually, pixels that have this value are in the form of water bodies or clouds. While pixels that have a value of 1 are the maximum value and mean that in the region it has very high vegetation conditions. In 2018, the image used is Landsat 8 OLI / TRIS with the recording date of August $14^{\text {th }}, 2018$. Fig. 3 shows the distribution of NDVI in the Kuningan Regency. The minimum value for this year is 0.16 and the maximum value is 0.58 . NDVI can be seen with a minimum value will be red, while NDVI with the maximum value will be green. NDVI with a minimum value is dominated in the middle spreading from west to east, while the maximum value diffuse in the north and south.

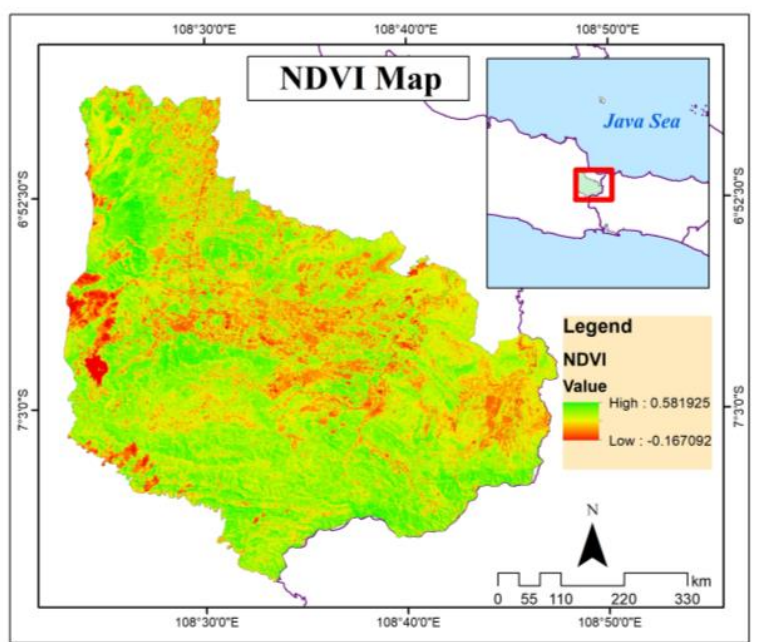

Fig. 3. NDVI of Kuningan Regency

\subsection{LST}

LST (Land Surface Temperature) is a value that reflects the temperature in the region. Fig. 4 is a description of the temperature distribution in dry months in 2018 in Kuningan Regency. To calculate the band LST value used is Thermal Band, which is Band 10 or 11 on Landsat $8 \mathrm{OLI} / \mathrm{TRIS}$. According to the results of data processing, the minimum value indicates $13.23^{\circ} \mathrm{C}$ while the maximum is $37.97^{\circ} \mathrm{C}$ (see Fig. 4). It can be seen if the minimum value of LST is spread in the west. The area is a mountain area, so the temperature in the area is low. While over the east the temperature tends to be higher because of the topography.

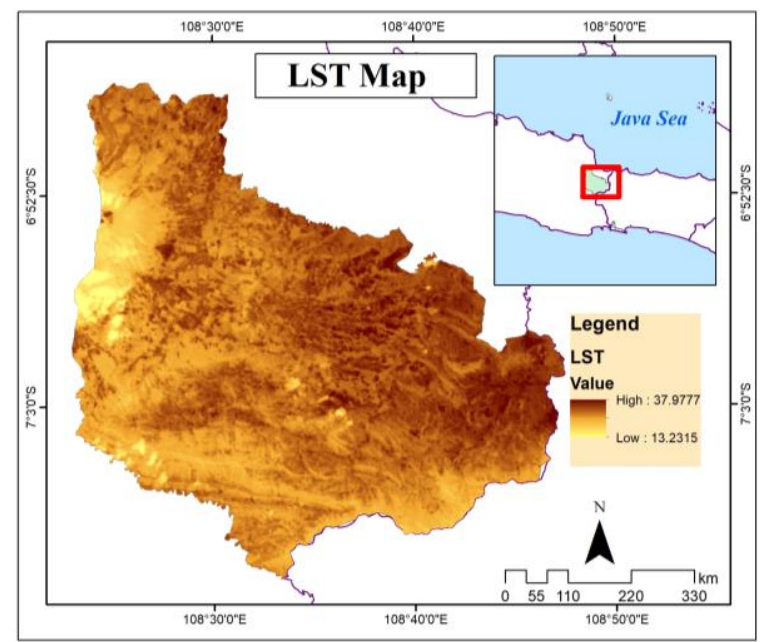

Fig. 4. LST of Kuningan Regency

\subsection{TVDI}

Fig. 5 shows the relationship between temperature (LST) and vegetation index (NDVI). The lower the LST value than the lower the NDVI value. This can be explained because when conditions of vegetation are high, heat will be absorbed by the vegetation causing a low temperature. And if the vegetation conditions are low, the media to absorb heat is also limited. The results show that at the wet edge (LSTmin) equation value is $\mathrm{y}=$ $2.2278 x+25.442$ while the dry edge (LST max) equation is $\mathrm{y}=-12.664 \mathrm{x}+340.33$ where $\mathrm{x}$ is the pixel value of NDVI. Based on the TVDI formula, then: TVDI $=(\mathrm{LST}-(-2.2278 * \mathrm{NDVI}+25.442)) /(-0.437 * \mathrm{NDVI}+8.591)$

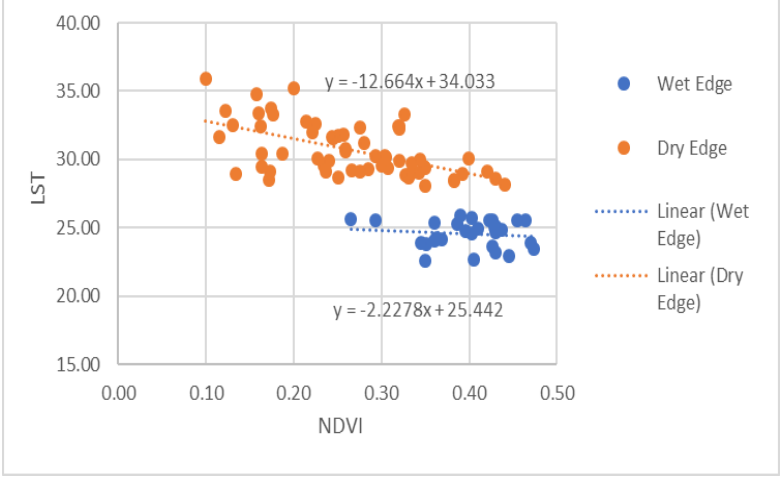

Fig. 5. Value of NDVI and LST 


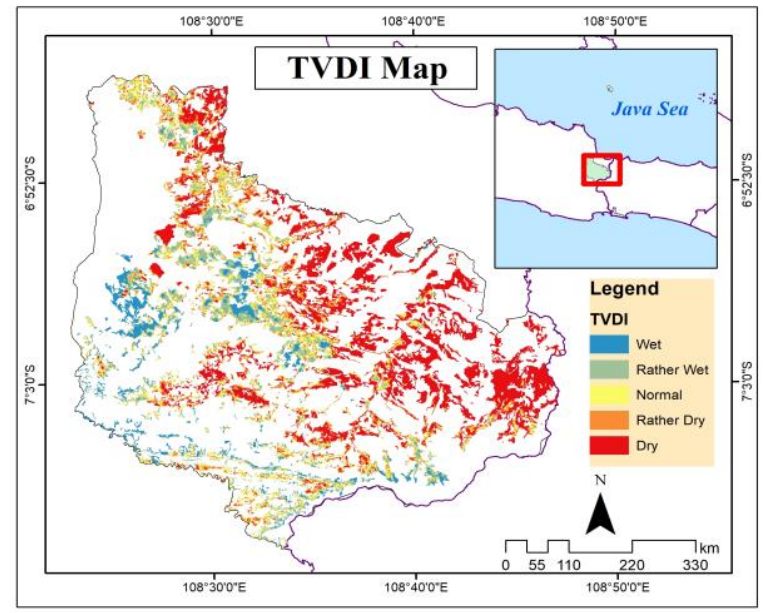

Fig. 6. TVDI of Paddy Fields

Fig.6 is a map of TVDI which has been clip with the use of paddy fields. It can be seen, there are all classes of drought in that period. TVDI with a wet class is spread in the west and a little in the middle. Then the rather wet classes are spread in the west with a small area, as well as the normal classes. Then the rather dry classes are barely visible on the map. The last dry classes are spread in the middle to the east and a little in the north.

Table 2. Area of TVDI

\begin{tabular}{|c|c|c|c|}
\hline No & Class & Area $\left.\mathbf{( k m}^{\mathbf{2}}\right)$ & Percentage \\
\hline 1 & Wet & 32.94 & $9 \%$ \\
\hline 2 & Rather Wet & 50.78 & $14 \%$ \\
\hline 3 & Normal & 60.93 & $17 \%$ \\
\hline 4 & Rather Dry & 57.45 & $16 \%$ \\
\hline 5 & Dry & 155.82 & $44 \%$ \\
\hline
\end{tabular}

Table 2 shows the area of rice fields based on drought class. The largest area is a region with a dry class that has an area of $155.83 \mathrm{~km}^{2}$ or $44 \%$ of the total. Then followed by the normal classes with an area of $60.93 \mathrm{~km}^{2}$ or $17 \%$. The rather dry class is in third place with an area of $57.45 \mathrm{~km}^{2}$ or $16 \%$, only $1 \%$ different from the normal classes. The last is the class rather wet and we with each area of $50.78 \mathrm{~km}^{2}(14 \%)$ and $32.94 \mathrm{~km}^{2}$ $(9 \%)$.

\section{Conclusion}

Based on the results of calculations, the LSTmin value is $\mathrm{y}=-2.2278^{*} \mathrm{NDVI}+25.442$ and the LSTmax value is $\mathrm{y}$ $=-12.664 * \mathrm{NDVI}+34.033$. So that the value of TVDI $=$ $(\mathrm{LST}-(-2.2278 * \mathrm{NDVI}+25,442)) /(--0.437 * \mathrm{NDVI}$ $+8.591)$. The TVDI class which has the widest area is a dry class with an area of $155.83 \mathrm{~km}^{2}$ or about $44 \%$ of the total area. Whereas the class with the smallest area is a wet class with an area of $32.94 \mathrm{~km}^{2}$ or about $9 \%$.

\section{References}

1. A. Yuwono, Environmental Damage Control and Climate Change, Jakarta : University of Indonesia (2012)

2. Shofiyati, Kuncoro. Inderaja to Assess Drought in Agricultural Land, Jurnal Informatika Pertanian 16(1) (2007)

3. F.H. White, A Study of the Feasibility of Using Simulation Models and Mathematical Programs as Aids to Drought Monitoring and Management, Bureau of Rural Resources, Canbera (1990)

4. I. Sandholt, K. Rasmussen, J. Andersen, A simple interpretation of the surface temperature/vegetation index space for assessment of surface moisture status, Remote Sensing of Environment 79, 213224 (2002)

5. Ardiansyah, Remote Sensing Image Processing Using ENVI 5.1 and LIDAR ENVI, Jakarta: PT Labsig Inderaja Islim (2015)

6. Parwati, et al. TVDI Index (Temperature Vegetation Drynesss Index) Model for for Detecting Land Drought Based on Modis-Terra Data, Jurnal Penginderaan Jauh 5, 35-44 (2008)

7. J. Andersen, et al. Perspective in Using A Remotely Sensed Dryness Index in Distributed Hydrological Models at the River-basin Scale, Hydrologival Processes 16, 2973-2987 (2002)

8. W. Suseno, Agricultural Drought Pattern on Java Island, Depok : University of Indonesia (2008) 